\title{
THE POSSIBILITY OF DEVELOPMENT IN THE TRANSMISSION OF ELECTRICAL ENERGY AND ITS EFFECT ON TOWNS
}

The centralising of the supply of power was one of the first developments which was suggested when electricity began to be used on a comparatively large scale in the eighties. In some lectures and papers written at that date, it was proposed that cottage industries might be established and the factory system considerably modified. These prognostications have not been fulfilled, for reasons which now appear obvious, and it is unlikely that any developments in the electrical transmission of power in England will produce any recrudescence of industrial conditions which are now recognised in many cases to be unhealthy, and which in most cases are uneconomical.

At that time the large schemes which are now in operation were hardly considered to be possible. The transmission of electric power at the Frankfort Exhibition in 1890, over a distance of 110 miles from the Falls at Lauffen, on the River Neckar, was the first practical experiment which showed to what lengths the economical distribution of power by electric means could be carried; but after that experiment it was many years before distribution on a large scale was carried out in practice. The most obvious case for long distance transmission occurs with a water-power plant when the source of the power is fixed by Nature and where the towns and factories which are to make use of the power are already in existence. Under these circumstances it is not remarkable that long distance transmission had grown most rapidly in countries where the supply of coal is small, but in which water power is plentiful. The outstanding examples of electrical transmission schemes are to be found in America, particularly in association with the Niagara Falls, though the longest distance transmissions are in operation on the Pacific slope of the United States, where coal is difficult to get, but where there is a considerable amount of water power. In connection with the supply of power to San Francisco there is now in operation a total length of line of over 1,000 miles, the longest distance between a transmitting and receiving station being 250 miles. The engineering problem as regards transmission of power over these distances may be regarded as solved, though there are, of course, many details which may yet be improved, which will lead to a better and more reliable service. The possibility of such systems in any country is very largely an economic one, though there are other factors which require consideration. 
It may be questioned whether there is the same "raison d'être" for long-distance transmission in England as there is in countries where the natural supply of power is confined to a particular place as it is in a water-power station. The early suggestions that were made in this country deal with the possibility of establishing great distributing centres at the coal pits, either at the surface or underground, but there are other sources of power which have been largely overlooked. Mr. Thwaite, an English engineer (who unfortunately reaped a very small benefit from his suggestion), was the first to propose that the blast-furnace gases which are obtained from steel furnaces might be employed for producing electrical energy. (It may be interesting to note that one of the large Power Companies in the North of England is now proposing to use blast-furnace gas, though not in the way Mr. Thwaite originally proposed.) Then again there is in England a small amount of water power which might be harnessed. At the present time there is just below Snowdon a power station capable of developing over 6,000 horse-power, and there must be, in many other parts of England, water power of at least as great amount which might be put to useful purposes. These natural sources of power can only be used if other conditions are favourable, and it becomes necessary to discuss some of the reasons which have led to long distance transmission being developed at so slow a pace in this country.

In the first place the only possible method for long distance transmission is absolutely determined on financial grounds, to be an overhead line. No one has seriously proposed a transmission scheme of 100 miles or more, using underground cables. Such a plan would be enormously costly and would hardly supply power at a rate which would enable it to be widely used. With an overhead line the question of "way leaves" is fundamental, and the difficulty of obtaining these at a reasonable rate, is one of the chief reasons for the slow progress in long distance transmission. Only a few weeks ago Mr. Woodhouse, the engineer to the Yorkshire Power Company, who has the largest length of overhead line in operation in England, was deploring the difficulties with which he was faced in this direction. The exorbitant demands of land-owners, the difficulties due to crossings of roads and railways make the lot of the transmission engineer a much less happy one than it is in countries with less dense populations and with more power over the land. For the sake of comparison it may be interesting to refer to the regulations in force in some American States. In these States the power companies have rights of expropriation and arbitration if they can show sufficient cause for a transmission line passing over a particular plot of land which the owner desires to protect. Although this plan would hardly be likely to find favour in this country, there seems little doubt that 
some legislation will be required if overhead lines are to be used to any great extent for the transmission of power. In the second place coal in England is very cheap and the problem of electrical transmission is very largely an economical one. The question that has to be answered is, "Is it more economical to transmit the power required as electrical power or in some other form?" This question can only be answered when the facts and figures relating to any particular scheme have been fully discussed and considered, but in most instances there is very little doubt that the electrical method, on purely economical grounds, will be found to be the best. The comparison in this country has to be made, between the cost of carrying coal and of carrying electrical power. A very interesting calculation of this kind has recently been made by Mr. Miles Walker, for an overhead transmission line between the coalfields in the Midlands and London. He estimated that apart from other obvious advantages a saving of $£ 120,000$ per annum could be effected if electrical energy were produced at the pit's mouth, transmitted at high pressure to London, and there used; instead of as at present, carrying the coal there and producing the electrical energy at the point where it was required. Another method of transmitting power that has been suggested is the conveyance of gas in pipes from gas producers located in the coal district to the place where the power is required. These schemes have, however, so far not been developed on any large scale chiefly because of the inherent difficulties in the operation of gas engines as compared with electric motors. Anyone who has had experience of these two types of machinery will have very little difficulty in deciding which is the most suitable in locations where there is no skilled labour. The greater ease of manipulation has done more to develop the use of electrical power in small works and factories than anything else, and with the increase in automatic controlling devices in connection with electrical machinery progress may be expected at an ever increasing rate. Electricity will be used more and more because of its applicability to all kinds of purposes. It can be employed for lighting the workshop and the house, as well as supplying all the motive power that may be wanted either for domestic or manufacturing operations. It may be used for lighting streets or for conveying passengers along them, and it will undoubtedly be used directly in the future for many manufacturing and industrial processes, and in the manufacture of iron and steel, aluminium, calcium carbide, and many other chemical products.

The more universal use of electrical energy will have an enormous influence on the appearance and healthiness of towns and cities. Consider for the moment what would be the result of the substitution of electricity for coal in all our railways. A very remarkable investigation 
has recently been undertaken in Chicago as to the amount of smoke which is caused by the trains running into that city. This investigation was undertaken at the instance of the City Authorities with the view to an application for compulsory powers to force the railway companies to electrify all lines running into the city (as has already been done in New York); the result of the investigation shows that over 18 per cent. of the coal brought within the city boundaries was burnt by steam locomotives running on tracks inside this area, that 43 per cent. of the total smoke produced was caused by the railway trains, and a weight of over 560 tons was deposited daily from the locomotives in the city area. Facts like these show how great the dirt and smoke caused by locomotives may be. Chicago is, of course, an exceptional town in that it is the centre through which practically all the wheat grown in the Western States of the Union is transported on its way east, besides being the greatest depot for all kinds of farm produce and cattle. The number of trains entering and leaving daily is greater than in any other city in the States, but it must be remembered also that the area included within the city boundary is a very large one.

Railway electrification, especially on suburban lines, has already done much and will do still more, it is to be hoped, in the future, in the purification of the atmosphere of towns, as well as in greatly increasing the comfort of the passengers that travel over them. Although railways are responsible for a great deal of the dirt of a modern town, the ordinary domestic fire is a far worse offender. Not only does the use of coal in houses greatly increase the amount of work of the domestic servant, but even before it is burnt it increases the labour involved in keeping a house clean. When the coal is burnt in most modern grates (though great improvements have been made of recent years in their construction) a large proportion of the heat of the coal goes up the chimney, and what is perhaps still worse, a large amount of smoke is produced. It is this smoke which goes to the atmosphere through the chimney and returns to the house through the window, which causes the greater part of the dirt, the removal of which is a large part of the problem of the modern city housewife. It is no exaggeration to say that the abolition of the domestic fire and cooking range would do more to solve the domestic problem (if a domestic problem may be said to exist in this country) than any other reform in the town life of to-day. The use of gas for heating has made great strides, greater perhaps than is generally realised. The engineer of the South London Gas Company stated recently that the heaviest load on the gas station of his Company occurs between 11 and 1 o'clock on Sunday mornings, when it is the custom of the housewife or landlady in his district to cook the Sunday dinner. The consumption of gas in 
the evening when the streets and houses are lit falls far short of that during the hours when gas fires are in greatest use. The influence of the use of gas fires on the atmosphere of the Metropolis is evidenced by the fact that the number of days of heavy fog during the past few years is only a fraction of what it was 20 or 30 years ago when the coal fire reigned supreme. Although gas fires give no smoke they give noxious products of combustion, and anyone who has gone through the transformation of house from gas to electric lighting cannot fail to be impressed by the greater purity of the atmosphere in the house where none of these fumes are produced. These products although they give no dirt must tend to devitalise the atmosphere of rooms, and it is on this ground mainly that the electric radiator must be regarded as a step in advance. Were it possible to light and heat our houses by electrical energy supplied by stations outside our cities, the atmosphere of our towns would be transformed, and cities would be very different places from what they are at present. Not only would the houses and public buildings be cleaner, but the atmosphere would be such as would enable trees and flowers to grow in a way that is unknown at present. Even the cities of to-day might be made, to a certain extent, garden cities. But the use of electrical energy for heating is not likely to progress very rapidly until the cost of a unit of electric energy is a fraction of what it is at present. It is outside the scope of this article to discuss the conditions which will enable the cost of electrical energy to be materially reduced, they are now well understood, and there is no question that if electrical development takes place along the right lines that electrical energy will be obtainable at rates which now appear beyond the realm of possibility. Mr. Ferranti in an address recently delivered before the Institution of Electrical Engineers gave it as his opinion that it would be possible to supply electrical energy at an average price of one-eighth of a penny per unit, and when that time comes, as it is bound to do sooner or later, electricity will be the universal servant. It will be used for lighting and for power, for heating and for railways; it has even been suggested that it may be used for controlling, to a certain extent, the weather, by causing the raindrops to condense and fall over defined areas.

E. W. Marchant. 